\title{
Lower CSF Homovanillic Acid Levels in Depressed Patients with a History of Alcoholism
}

\author{
Leo Sher*,', Maria A Oquendo', Shuhua Li', Yung-yu Huang', Michael F Grunebaum', Ainsley K Burke', \\ Kevin M Malone' and J John Mann' \\ 'Division of Neuroscience, Department of Psychiatry, Columbia University, New York, NY, USA
}

\begin{abstract}
Major depression and alcoholism are often comorbid, resulting in more impairment and more suicidal behavior compared with either diagnosis alone. This study compared clinical features and cerebrospinal fluid (CSF) monoamine metabolites in depressed subjects with and without a history of alcoholism and healthy volunteers. We hypothesized that depressed subjects with a history of alcoholism would be more aggressive, impulsive, and suicidal than depressed subjects without a history of alcoholism, and would have lower CSF monoamine metabolite levels. We compared 63 subjects with a current major depressive episode (MDE) and a history of alcoholism, 72 subjects with a current MDE but without a history of alcoholism, and 22 healthy volunteers. Participants with a history of alcoholism were in remission for at least 6 months. All subjects were free from prescribed medications known to affect brain serotonin, dopamine, or norepinephrine systems for a minimum of 14 days. Depressive symptoms, lifetime aggression, impulsivity, Axis II disorders, and suicidal behavior were assessed. CSF was sampled and homovanillic acid (HVA), 5-hydroxyindolacetic acid (5-HIAA), and 3-methoxy-4hydroxyphenylglycol (MHPG) were assayed by high-performance lipid chromatography with electrochemical detection. Depressed subjects with a history of alcoholism did not differ from depressed subjects without a history of alcoholism in current severity of depressive symptoms, or in past suicidal behavior. Depressed subjects with a history of alcoholism had lower CSF HVA levels, and higher lifetime aggression and current suicide ideation scale scores and were more likely to be tobacco smokers compared with depressed subjects without a history of alcoholism. Low HVA was present after adjustment for sex, aggression and depression scores, cigarette smoking, antisocial and borderline personality disorders, psychomotor retardation, and delusions. Controls had CSF HVA levels intermediate between the two depressed groups. We found no group difference in CSF 5-HIAA and MHPG levels. In individuals with current MDE, those with a history of comorbid alcoholism had lower CSF HVA levels compared with those without a history of alcoholism. Low CSF HVA suggests that impaired dopaminergic activity is associated with a history of alcoholism in persons with current MDE.
\end{abstract}

Neuropsychopharmacology (2003) 28, 1712-1719, advance online publication, 25 June 2003; doi: I0.1038/sj.npp. 130023 I

Keywords: depression; alcoholism; cerebrospinal fluid; dopamine; homovanillic acid

\section{INTRODUCTION}

Alcohol abuse and dependence (alcoholism) with their high morbidity and mortality are a major public health problem in the US and worldwide (Nelson and Stussman, 1994; Greenfield and Weisner, 1995; Grant, 1997). A total of 13\% of the adult population in the United States has a history of alcohol abuse or alcohol dependence (Grant, 1997). Major depressive disorder is also a significant health issue. The lifetime prevalence of major depression is $5-12 \%$ for men

*Correspondence: Dr L Sher, Division of Neuroscience, Department of Psychiatry, Columbia University, 1051 Riverside Drive, Suite 2917, Box 42, New York, NY 10032, Tel: + I 212543 6240, Fax: + I 212 543 6017, E-mail: leosher@neuron.cpmc.columbia.edu

Received 05 November 2002; revised 24 April 2003; accepted 12 May 2003

Online publication: 16 May 2003 at http://www.acnp.org/citations/ Npp05 I 60240 I/default.pdf and $10-25 \%$ for women (American Psychiatric Association, 1994; Blazer et al, 1994; Gruenberg and Goldstein, 1997). The National Comorbidity Survey estimates overall lifetime prevalence of major depressive disorder as $17.1 \%$ (Blazer et al, 1994). Major depression often results in impaired interpersonal, social, and occupational functioning. Recent findings identify both major depression- and alcoholrelated disorders in the top diseases that are associated with disability and costs (Murray and Lopez, 1997).

Major depression and alcoholism are often comorbid (Schuckit, 1986; O'Sullivan et al, 1988; Herz et al, 1990; Buydens-Branchey et al, 1989; Roy et al, 1991a, b; Cornelius et al, 1995, 1996; Davidson and Blackburn, 1998; Spak et al, 2000; McGrath et al, 2000; Gilman and Abraham, 2001; Thase et al, 2001). Schuckit (1986), suggests that between one-quarter and two-thirds of subjects with alcoholism have had depressive symptoms severe enough to interfere with functioning. Depressed subjects with alcoholism have more 
chronic impairment and suicidal behavior than individuals with either diagnosis alone (O'Sullivan et al, 1988; Cornelius et al, 1995, 1996; Thase et al, 2001).

Brain dopaminergic, serotonergic, and noradrenergic systems have been implicated in biological mechanisms of both depression and alcoholism (for reviews, see Nemeroff et al, 1997; Fromme and D'Amico, 1999; Geracioti, 1997; Koob, 1992; Kapur and Mann, 1992; Nevo and Hamon, 1995; Oquendo and Mann, 2000; Valenzuela and Harris, 1997; Schatzberg et al, 2002). The cerebrospinal fluid (CSF) concentrations of the dopamine, serotonin, and to a lesser degree norepinephrine metabolites, homovanillic acid (HVA), 5-hydroxyindoleacetic acid (5-HIAA), and 3-methoxy-4-hydroxyphenylglycol (MHPG), respectively, are presumed to reflect the turnover of parent neurotransmitters in the central nervous system (Moir et al, 1970; Bowers, 1972; Stanley et al, 1985; Sharma et al, 1994; Reuster et al, 2002). Accordingly, measurements of these compounds in lumbar CSF have been employed in studies of brain function in vivo.

Roy et al (1991a) found lower CSF levels of the dopamine metabolite HVA in depressed compared with never depressed subjects with alcohol dependence. Although multiple studies have shown changes in CSF monoamine metabolites in subjects with alcoholism (Roos and Silfverskiöld, 1973; Kato et al, 1979; Goldman et al, 1992; Takahashi et al, 1974; Major et al, 1977; Fujimoto et al, 1983; Virkkunen et al, 1996; Fils-Aime et al, 1996; Petrakis et al, 1999; Adinoff et al, 1996, 1995, 1991; Geracioti et al, 1994, 1993; Virkkunen et al, 1994; Kaakkola et al, 1993; Roy et al, 1990; Roy and Linnoila, 1989; Hawley et al, 1988; Borg et al, 1982; Geracioti, 1997), the study by Roy et al (1991a), to our knowledge, is the only study that measured CSF HVA in depressed individuals with alcoholism. Most studies do not distinguish possible biological effects of related psychopathology such as depression, psychosis, suicidal behavior, or smoking.

This is the first study to compare CSF monoamine metabolites and clinical features in depressed subjects with and without a history of alcoholism and healthy controls. We hypothesized that depressed subjects with a history of alcoholism would be more suicidal, aggressive, and impulsive than depressed subjects without a history of alcoholism and healthy controls and that CSF monoamine levels would be lower in depressed subjects with a history of alcoholism. We also evaluated the effects of psychosis, psychomotor change, and cigarette smoking.

\section{MATERIAL AND METHODS}

\section{Subjects}

Participants were recruited through advertising and referrals and admitted to a university hospital for participation in mood disorders research. All subjects gave written informed consent as required by the Institutional Review Board for Biomedical Research. In all, 72 depressed subjects without a history of any alcohol or substance abuse/ dependence (19 males and 53 females), 63 depressed subjects with a history of alcoholism (35 males and 28 females), and 22 healthy volunteers (10 males and 12 females) participated in the study. In all, 58 depressed subjects without a history of alcoholism and 55 depressed subjects with a history of alcoholism were inpatients. A total of 14 depressed subjects without a history of alcoholism and eight depressed subjects with a history of alcoholism were treated as outpatients. All met DSM-IV (American Psychiatric Association, 1994) criteria for a current major depressive episode (MDE). Participants had to be free from prescribed medications known to affect brain serotonin, dopamine, or norepinephrine systems for a minimum of 14 days. The drug-free interval was longer for drugs with a long half-life (6 weeks for fluoxetine and 4 weeks for oral antipsychotics). Among psychotropics, only small doses of short-acting benzodiazepines were permitted but not $72 \mathrm{~h}$ before the lumbar puncture. Individuals with a history of alcoholism were free from alcohol dependence for at least 6 months, therefore the current episode of major depression was independent, that is, not alcohol induced. Subjects were free from any substance abuse for at least 2 months. The duration of the drug-free status of the subjects was established by a combination of urine and blood toxicological screenings, observation in hospital, and a history obtained from the participant, the participant's family, and the referring physician. Subjects with current symptoms of alcohol/drug withdrawal states were not accepted in the study. Subjects were not allowed to smoke for $12 \mathrm{~h}$ before the lumbar puncture.

DSM-IV Axis I and Axis II disorders were diagnosed using the Structured Clinical Interview I (SCID-I) and the Structured Clinical Interview II (SCID-II), respectively, for DSM-IV (American Psychiatric Association, 1994). Healthy controls were recruited through advertising and were free of psychiatric disorder based on the SCID-NP (nonpatient version). All subjects had a physical examination and routine laboratory screening tests, including urine and blood toxicological screenings, to rule out neurological or medical illness that could affect their mental status or CSF monoamine metabolites.

The current severity of depression was assessed by the Hamilton Depression Rating Scale (HDRS) (Hamilton, 1960) and the Beck Depression Inventory (BDI) (Beck et al, 1961). Lifetime aggression and impulsivity were assessed with the Aggression History Scale (Brown-Goodwin, revised) (Brown and Goodwin, 1986) and the Barratt Impulsivity Scale (Barratt, 1965), respectively. Current hopelessness was measured with the Beck Hopelessness Scale (Beck et al, 1974b). Current suicidal ideation was measured by the Scale for Suicidal Ideation (SSI) (Beck et al, 1979). Details of lifetime suicide attempts were recorded on the Columbia Suicide History Form, which records all suicide attempts chronologically, including documentation of the method and degree of medical damage (Medical Damage Scale) and suicidal intent by the Beck Suicide Intent Scale (SIS) (Beck et al, 1974a). Symptoms were measured within 14 days from the lumbar puncture.

\section{The Lumbar Puncture and CSF Monoamine Metabolites Assay}

The lumbar puncture was performed at about 08:00 h, after the subject had been kept at bed rest and fasting from midnight. The CSF was withdrawn from the L4-L5 interspace, with the subject in the left decubitus position. After 
the removal of $1 \mathrm{ml}$ of CSF into the first sample tube, a further $15 \mathrm{ml}$ of CSF was collected in the second and third tubes. These tubes were then immediately transferred on ice water to be centrifuged at $4^{\circ} \mathrm{C}$, and the supernatant pooled from the second and third tubes. The $15 \mathrm{ml}$ of supernatant was divided into $1-\mathrm{ml}$ aliquots for storage at $-70^{\circ} \mathrm{C}$ until assay. CSF amine metabolites were assayed in one of the 1$\mathrm{ml}$ aliquots of the $15-\mathrm{ml}$ sample.

CSF HVA, 5-HIAA, and MHPG were assayed by highperformance liquid chromatography with electrochemical detection (Scheinin et al, 1983). The within- and betweenrun coefficients of variance of the assay were less than $10 \%$. The sensitivity of the assay was $0.5 \mathrm{pmol} /$ injection. All samples were kept frozen until assay. Storage effects were not detected.

\section{Statistical Analyses}

Gender distribution of subjects was evaluated with the $\chi^{2}$ test. Demographic and clinical characteristics and CSF monoamine metabolites in depressed subjects with and without a history of alcoholism and healthy volunteers were compared using a general linear model. We compared CSF HVA in the two depressed groups controlling for sex, aggression, and depression (HDRS) scores, tobacco smoking, antisocial and borderline personality disorders, psychomotor retardation, and delusions because studies have suggested that these parameters may affect the CSF HVA content (Raleigh et al, 1992; Nordin et al, 1995; Seegal, 1985; Campanella et al, 1977; Lindstrom, 1985; Aberg-Wistedt et al, 1985; Houston et al, 1986; Almay et al, 1987; Jones et al, 1990; Faustman et al, 1991; Limson et al, 1991; Spiegel and King, 1992; Johnson et al, 1994; Soderstrom et al, 2001; Kapur and Mann, 1992; Brown and Gershon, 1993; Lykouras et al, 1994; van Praag et al, 1975; Post et al, 1973; Chotai et al, 1998; Daderman and Lidberg, 2002; Geracioti et al, 1999). Suicide attempt status was evaluated using the chisquared test. All tests were two-tailed and significance required $P<0.05$.

\section{RESULTS}

\section{Demographic and Clinical Characteristics}

We compared demographic and clinical characteristics and CSF monoamine metabolites in the three groups (Tables 1 and 2). There were fewer females (44.4\%) than males in the group with a history of alcoholism compared with the group without a history of alcoholism ( $73.6 \%$ females) and healthy controls $(54.5 \%$ females $)\left(\mathrm{df}=2, \chi^{2}=12.1, P=0.002\right)$. The group with a history of alcoholism had fewer years of education than controls (Table 1). The two depressed groups did not differ in the percentage of inpatients/ outpatients $\left(\mathrm{df}=1, \chi^{2}=1.1, P=0.3\right)$ or suicide attempters $\left(\mathrm{df}=1, \chi^{2}=1.7, P=0.2\right)$.

Table I Demographic and Clinical Characteristics of Depressed Subjects and Healthy Volunteers

\begin{tabular}{|c|c|c|c|c|c|c|c|c|c|}
\hline \multirow[b]{2}{*}{ Measure } & \multicolumn{2}{|c|}{$\begin{array}{l}\text { Controls } \\
(n=22)\end{array}$} & \multicolumn{2}{|c|}{$\begin{array}{l}\text { Subjects without a history of } \\
\text { alcohol dependence }(n=72)\end{array}$} & \multicolumn{2}{|c|}{$\begin{array}{l}\text { Subjects with a history of } \\
\text { alcohol dependence }(n=63)\end{array}$} & \multicolumn{3}{|c|}{ Analysis } \\
\hline & Mean & SD & Mean & SD & Mean & SD & df & $F / t$ & $P$ \\
\hline Total years of education & 16.9 & 1.6 & 15.4 & 3.0 & 14.6 & 2.7 & 2140 & 4.7 & $0.01^{\mathrm{a}}$ \\
\hline Number of previous depressive episodes & N/A & $\mathrm{N} / \mathrm{A}$ & 4.6 & 7.1 & 6.0 & 13.6 & 120 & 0.7 & 0.4 \\
\hline Age of onset of the first depressive episode & N/A & $\mathrm{N} / \mathrm{A}$ & 25.7 & 13.7 & 23.6 & 11.7 & 125 & -1.0 & 0.3 \\
\hline Aggression History Scale & 14.2 & 3.7 & 16.7 & 5.0 & 21.5 & 6.0 & 2147 & 20.1 & $<\left.0.000\right|^{a, c}$ \\
\hline Barrat Impulsivity Scale (BIS) & 34.0 & 10.8 & 50.9 & 15.5 & 57.9 & 19.2 & 2125 & 15.1 & $<\left.0.000\right|^{a, b}$ \\
\hline Beck Hopelessness Scale & 1.7 & 2.4 & 13.5 & 5.3 & 11.8 & 5.3 & 2143 & 43.5 & $<0.0001^{\mathrm{a}, \mathrm{b}}$ \\
\hline Age at first suicide attempt & N/A & $\mathrm{N} / \mathrm{A}$ & 27.6 & $\mid 3.1$ & 25.4 & 13.5 & । & 0.5 & 0.5 \\
\hline Suicidal Ideation Scale & N/A & $N / A$ & 13.2 & 10.3 & 16.8 & 10.7 & 132 & 2.0 & $<0.05$ \\
\hline SIS & $N / A$ & $N / A$ & 16.8 & 5.5 & 17.2 & 5.5 & 80 & 0.4 & 0.7 \\
\hline Number of suicide attempts in attempters & N/A & $\mathrm{N} / \mathrm{A}$ & 3.1 & 3.2 & 3.0 & 2.1 & 77 & -0.3 & 0.8 \\
\hline
\end{tabular}

${ }^{a}$ Controls are different from depressed subjects with a history of alcohol dependence at 0.05 .

${ }^{b}$ Controls are different from depressed subjects without a history of alcohol dependence at 0.05 .

cDepressed subjects with a history of alcohol dependence are different from depressed subjects without a history of alcohol dependence at 0.05 .

Table 2 CSF Monoamine Metabolites in Depressed Subjects with and without a History of Alcohol Dependence and Healthy Volunteers

\begin{tabular}{|c|c|c|c|c|c|c|c|c|c|}
\hline & \multicolumn{2}{|c|}{$\begin{array}{l}\text { Controls } \\
(n=22)\end{array}$} & \multicolumn{2}{|c|}{$\begin{array}{l}\text { Subjects without a history of } \\
\text { alcohol dependence }(n=72)\end{array}$} & \multicolumn{2}{|c|}{$\begin{array}{c}\text { Subjects with a history of } \\
\text { alcohol dependence }(n=63)\end{array}$} & \multicolumn{3}{|c|}{ Analysis } \\
\hline & Mean & SD & Mean & SD & Mean & SD & df & $\boldsymbol{F}$ & $\mathbf{P}$ \\
\hline $5-\mathrm{HIAA}(\mathrm{pmol} / \mathrm{ml})$ & 94.0 & 35.3 & 103.9 & 34.1 & 95.9 & 33.6 & 2154 & 1.2 & 0.3 \\
\hline MHPG $(\mathrm{pmol} / \mathrm{ml})$ & 39.2 & 22.1 & 43.4 & 16.9 & 38.6 & 13.5 & 2154 & 1.5 & 0.2 \\
\hline
\end{tabular}

${ }^{a}$ Depressed subjects with a history of alcohol dependence are different from depressed subjects without a history of alcohol dependence at 0.05 . 
A total of $59.7 \%$ of depressed subjects with a history of alcoholism and $21.1 \%$ of depressed subjects without a history of alcoholism were tobacco smokers $(\mathrm{df}=1$, $\left.\chi^{2}=20.7, \quad P<0.0001\right)$. There were no tobacco smokers among normal controls.

In all, $28(44.4 \%)$ depressed subjects with a history of alcoholism and 23 (31.9\%) depressed subjects without a history of alcoholism had borderline personality disorder; $10(15.9 \%)$ depressed subjects with a history of alcoholism had antisocial personality disorder, including $6(9.5 \%)$ subjects who had both antisocial and borderline personality disorders. There were no subjects with antisocial personality disorder among depressed subjects without a history of alcoholism.

The depressed groups had comparable HDRS and BDI scores but higher than controls. Age of onset of the first depressive episode, number of previous depressive episodes, and suicidal behavior did not differ between the two depressed groups (Table 1). The depressed group with a history of alcoholism had higher lifetime aggression compared with the depressed group without a history of alcoholism and controls (Table 1). The depressed group with a history of alcoholism had higher aggression scores than the depressed group without a history of alcoholism after adjustment for antisocial $(\mathrm{F}=14.8, P<0.001)$ or borderline $(\mathrm{F}=22.2, \quad P<0.0001)$ personality disorders. Subjects with a history of alcoholism had higher current suicidal ideation scale score than subjects without a history of alcoholism (Table 1).

\section{CSF Monoamine Levels}

CSF HVA levels were lower in depressed subjects with a history of alcoholism compared with depressed subjects without a history of alcoholism $(\mathrm{df}=2,154, \mathrm{~F}=4.6$, $P=0.01$ ) (Table 2). The difference in the CSF HVA levels between the two groups remains statistically significant after adjustment for sex, aggression and depression (HDRS) scores, cigarette smoking, antisocial and borderline personality disorders, psychomotor retardation, and delusions $(\mathrm{df}=1, \mathrm{~F}=7.4, P=0.008)$. CSF HVA was correlated with CSF 5-HIAA $(r=0.6, P<0.0001)$ and CSF MHPG $(r=0.3$, $P=0.001)$. We did not find any correlations between the CSF monoamine metabolite concentrations and severity of the behavioral measures. Healthy volunteers had HVA levels intermediate between the two depressed groups and there were no statistically significant differences in the CSF 5HIAA, CSF HVA, and CSF MHPG levels between controls and either of the two depressed groups (Table 2).

\section{DISCUSSION}

\section{Clinical Features}

The results of our study indicate that depressed subjects with a history of alcoholism are more aggressive than depressed subjects without a history of alcoholism and healthy volunteers. This was the case even when antisocial and borderline personality disorders were taken into account. In addition, depressed subjects with a history of alcoholism reported more current suicidal ideation than depressed subjects without a history of alcoholism. These findings are consistent with reports that subjects with alcoholism are more aggressive and impulsive, and have more suicidal ideation than controls or psychiatric subjects without a history of alcoholism (Nicholls et al, 1974; Hesselbrock et al, 1985; Zucker and Gomberg, 1986; Cloninger et al, 1988; Cornelius et al, 1995, 2001; Bates and Labouvie, 1995; Caspi et al, 1997; Badawy, 1998; Pihl and LeMarquand, 1998; Sher et al, 1999). Prospective studies have demonstrated that impulsive individuals are at elevated risk for the development of alcohol-related problems (Bates and Labouvie, 1995; Caspi et al, 1997; Cloninger et al, 1988; Zucker and Gomberg, 1986; Sher et al, 1999). Aggressive and impulsive behaviors may be a manifestation of underlying personality pathology, or signs of a developmental disorder, or both, that contribute to the development of alcoholism (Sher et al, 1999).

\section{Biological Findings}

We found that CSF HVA was lower in depressed subjects with a history of alcoholism than in subjects without a history of alcoholism, even after adjustment for sex, aggression and depression (HDRS) scores, cigarette smoking, antisocial and borderline personality disorders, psychomotor retardation, and delusions. Our findings are consistent with previous reports that alcoholism affects CSF HVA levels (Roos and Silfverskiöld, 1973; Kato et al, 1979; Goldman et al, 1992; Takahashi et al, 1974; Major et al, 1977; Fujimoto et al, 1983; Roy et al, 1991a; Virkkunen et al, 1996; Fils-Aime et al, 1996; Petrakis et al, 1999). Roy et al (1991a) reported that depressed subjects with alcoholism had significantly lower concentrations of HVA than never depressed subjects with alcoholism. We did not have a never depressed group with a history of alcoholism, however, we found that depressed subjects with alcoholism had significantly lower levels of HVA than depressed subjects who had never had alcoholism. CSF HVA reflects CNS dopamine turnover (Bowers, 1972; Stanley et al, 1985) and our finding suggests that less dopaminergic activity is associated with alcoholism among depressed persons.

The CSF HVA levels in our control group are consistent with values reported in healthy volunteers (Takahashi et al, 1974; Kato et al, 1979; Roos and Silfverskiöld, 1973; Roy et al, 1990; Hibbeln et al, 1998; Westenberg and Verhoeven, 1988; Koslow et al, 1983; Kanemaru et al, 1998; Engstrom et al, 1999). Some studies have found lower CSF HVA level in subjects with depression (for reviews, see Kapur and Mann, 1992; Brown and Gershon, 1993; Nemeroff et al, 1997). However, the mean CSF HVA level of depressed subjects without a history of alcoholism in our study is higher than reported by other researchers who studied depressed subjects (Takahashi et al, 1974; Kato et al, 1979; Placidi et al, 2001; Åsberg et al, 1984; Reddy et al, 1992; Westenberg and Verhoeven, 1988; Koslow et al, 1983). This difference may be related to the fact that we used a sample of depressed subjects without a history of alcoholism. Our finding appears to be consistent with the study by Vestergaard et al (1978), who reported significantly higher CSF HVA levels in depressed subjects than in healthy controls. It is possible that the variability in the rates of comorbid alcoholism and/or other comorbid disorders in different depressed populations plays an important role in 
the inconsistency of findings regarding CSF HVA levels in depressed subjects. Low CSF HVA may have more to do with psychopathology related to alcoholism as opposed to mood disorder biology. Our finding is consistent with studies that suggest that dopaminergic mechanisms play a part in the biology of alcohol use disorders, including mechanisms of alcohol dependence and withdrawal (Diana et al, 1993; Weiss et al, 1996; Weiss and Koob, 1991; Koob, 1992; Noble, 1996; Wiesbeck et al, 2000; Fromme and D'Amico, 1999; Nevo and Hamon, 1995; Roos and Silfverskiöld, 1973; Kato et al, 1979; Goldman et al, 1992; Takahashi et al, 1974; Major et al, 1977; Fujimoto et al, 1983; Roy et al, 1991a; Virkkunen et al, 1996; Fils-Aime et al, 1996; Petrakis et al, 1999; Samson et al, 1990; Valenzuela and Harris, 1997; Robinson and Berridge, 1993; VavrousekJakuba et al, 1992; Quarfordt et al, 1991; Modell et al, 1993; Grace, 2000).

The absence of data on age-at-onset of alcoholism and subjects' quantity and frequency of alcohol use are limitations of our study. There is also a possibility of a selection bias because only subjects who volunteered to participate in a research program and were able to tolerate a medication washout were included in the study. In addition, the subjects were mostly inpatients.

The results of our study demonstrate that depressed subjects with a history of alcoholism are more aggressive, have more suicidal ideation and lower CSF HVA levels than depressed subjects who do not have a history of alcoholism. The differences in aggression and suicidality may partially explain higher morbidity and mortality among depressed subjects with alcoholism. Future studies are needed to explore the neurobiology of alcoholism, including relationships between CSF monoaminergic metabolites, depression with and without comorbid alcoholism.

\section{ACKNOWLEDGEMENTS}

This work was partly supported by MH62185 and MH48514.

\section{REFERENCES}

Aberg-Wistedt A, Wistedt B, Bertilsson L (1985). Higher CSF levels of HVA and 5-HIAA in delusional compared to nondelusional depression. Arch Gen Psychiatry 42: 925-926.

Adinoff B, Anton R, Linnoila M, Guidotti A, Nemeroff CB, Bissette G (1996). Cerebrospinal fluid concentrations of corticotropinreleasing hormone (CRH) and diazepam-binding inhibitor (DBI) during alcohol withdrawal and abstinence. Neuropsychopharmacology 15: 288-295.

Adinoff B, Kramer GL, Petty F (1995). Levels of gammaaminobutyric acid in cerebrospinal fluid and plasma during alcohol withdrawal. Psychiatry Res 59: 137-144.

Adinoff B, Nemeroff CB, Bissette G, Martin PR, Linnoila M (1991). Inverse relationship between CSF TRH concentrations and the TSH response to TRH in abstinent alcohol-dependent patients. Am J Psychiatry 148: 1586-1588.

Almay BG, Haggendal J, von Knorring L, Oreland L (1987). 5-HIAA and HVA in CSF in patients with idiopathic pain disorders. Biol Psychiatry 22: 403-412.

American Psychiatric Association (1994). Diagnostic and Statistical Manual of Mental Disorders (DSM-IV). APA Press: Washington, DC.
Asberg M, Bertilsson L, Martensson B, Scalia-Tomba GP, Thoren P, Traskman-Bendz L (1984). CSF monoamine metabolites in melancholia. Acta Psychiatr Scand 69: 201-219.

Badawy AAB (1998). Alcohol, aggression and serotonin: metabolic aspects. Alcohol Alcoholism 33: 66-72.

Barratt ES (1965). Factor analysis of some psychometric measures of impulsiveness and anxiety. Psychol Rep 16: 547-554.

Bates ME, Labouvie EW (1995). Personality-environment constellations and alcohol use: a process-oriented study of intraindividual change during adolescence. Psychol Addict Behav 9: 23-35.

Beck AT, Kovacs M, Weissman A (1979). Assessment of suicidal intention: the scale for suicide ideation. J Consult Clin Psychol 47: 343-352.

Beck RW, Morris JB, Beck AT (1974a). Cross-validation of the suicidal intent scale. Psychol Rep 34: 445-446.

Beck AT, Ward CH, Mendelson M, Mock J, Erbaugh J (1961). An inventory for measuring depression. Arch Gen Psychiatry 4: 53-63.

Beck AT, Weissman A, Lester D, Trexler L (1974b). The measurement of pessimism: the hopelessness scale. J Consult Clin Psychol 42: 861-865.

Blazer DG, Kessler RC, McGonagle KA, Swartz MS (1994). The prevalence and distribution of major depression in a national community sample: the National Comorbidity Survey. Am J Psychiatry 151: 979-986.

Borg S, Kvande H, Rydberg U, Terenius L, Wahlstrom A (1982). Endorphin levels in human cerebrospinal fluid during alcohol intoxication and withdrawal. Psychopharmacology (Berl) 78: 101-103.

Bowers Jr M (1972). Clinical measurements of central dopamine and 5-hydroxytryptamine metabolism: reliability and interpretation of cerebrospinal fluid acid monoamine metabolite measures. Neuropharmacology 11: 101-111.

Brown AS, Gershon S (1993). Dopamine and depression. J Neural Transm Gen Sect 91: 75-109.

Brown GL, Goodwin FK (1986). Human aggression and suicide. Suicide Life Threat Behav 16: 223-243.

Buydens-Branchey L, Branchey MH, Noumair D (1989). Age of alcoholism onset. I. Relationship to psychopathology. Arch Gen Psychiatry 46: 225-230.

Campanella G, Algeri S, Cerletti C, Dolfini E, Jori A, Rinaldi F (1977). Correlation of clinical symptoms, HVA and 5-HIAA in csf and plasma L-DOPA in Parkinsonian patients treated with L-DOPA and L-DOPA+RO 4-4602. Eur J Clin Pharmacol 11: 255-261.

Caspi A, Begg D, Dickson N, Harrington H, Langley J, Moffitt TE et al (1997). Personality differences predict health-risk behaviors in young adulthood: evidence from a longitudinal study. J Pers Soc Psychol 73: 1052-1063.

Chotai J, Kullgren G, Asberg M (1998). CSF monoamine metabolites in relation to the diagnostic interview for borderline patients (DIB). Neuropsychobiology 38: 207-212.

Cloninger CR, Sigvardsson S, Bohman M (1988). Childhood personality predicts alcohol abuse in young adults. Alcohol Clin Exp Res 12: 494-505.

Cornelius JR, Salloum IM, Day NL, Thase ME, Mann JJ (1996). Patterns of suicidality and alcohol use in alcoholics with major depression. Alcohol Clin Exp Res 20: 1451-1455.

Cornelius JR, Salloum IM, Lynch K, Clark DB, Mann JJ (2001). Treating the substance-abusing suicidal patient. Ann NY Acad Sci 932: 78-90.

Cornelius JR, Salloum IM, Mezzich J, Cornelius MD, Fabrega Jr H, Ehler JG et al (1995). Disproportionate suicidality in patients with comorbid major depression and alcoholism. $A m J$ Psychiatry 152: 358-364.

Daderman AM, Lidberg L (2002). Relapse in violent crime in relation to cerebrospinal fluid monoamine metabolites (5-HIAA, 
HVA and HMPG) in male forensic psychiatric patients convicted of murder: a 16-year follow-up. Acta Psychiatr Scand 106(Suppl 412): 71-74.

Davidson KM, Blackburn IM (1998). Co-morbid depression and drinking outcome in those with alcohol dependence. Alcohol Alcoholism 33: 482-487.

Diana M, Pistis M, Carboni S, Gessa GL, Rossetti ZL (1993). Profound decrement of mesolimbic dopaminergic neuronal activity during ethanol withdrawal syndrome in rats: electrophysiological and biochemical evidence. Proc Natl Acad Sci USA 90: 7966-7969.

Engstrom G, Alling C, Blennow K, Regnell G, Traskman-Bendz L (1999). Reduced cerebrospinal HVA concentrations and HVA/5HIAA ratios in suicide attempters. Monoamine metabolites in 120 suicide attempters and 47 controls. Eur Neuropsychopharmacol 9: 399-405.

Faustman WO, King RJ, Faull KF, Moses Jr JA, Benson KL, Zarcone VP et al (1991). MMPI measures of impulsivity and depression correlate with CSF 5-HIAA and HVA in depression but not schizophrenia. J Affect Disord 22: 235-239.

Fils-Aime ML, Eckardt MJ, George DT, Brown GL, Mefford I, Linnoila M (1996). Early-onset alcoholics have lower cerebrospinal fluid 5-hydroxyindoleacetic acid levels than late-onset alcoholics. Arch Gen Psychiatry 53: 211-216.

Fromme K, D'Amico EJ (1999). Neurobiological bases of alcohol's psychological effects. In: Leonard KE, Blane HT (eds) Psychological Theories of Drinking and Alcoholism. Guilford Press: New York. pp 422-455.

Fujimoto A, Nagao T, Ebara T, Sato M, Otsuki S (1983). Cerebrospinal fluid monoamine metabolites during alcohol withdrawal syndrome and recovered state. Biol Psychiatry 18: 1141-1152.

Geracioti Jr TD (1997). Cerebrospinal fluid neuroendocrinology of alcohol misusers. Addict Biol 2: 401-409.

Geracioti Jr TD, Loosen PT, Ebert MH, Ekhator NN, Burns D, Nicholson WE et al (1994). Concentrations of corticotropinreleasing hormone, norepinephrine, MHPG, 5-hydroxyindoleacetic acid, and tryptophan in the cerebrospinal fluid of alcoholic patients: serial sampling studies. Neuroendocrinology 60: 635-642.

Geracioti Jr TD, Nicholson WE, Orth DN, Ekhator NN, Loosen PT (1993). Cholecystokinin in human cerebrospinal fluid: concentrations, dynamics, molecular forms and relationship to fasting and feeding in health, depression and alcoholism. Brain Res 629: 260-268.

Geracioti Jr TD, West SA, Baker DG, Hill KK, Ekhator NN, Wortman MD et al (1999). Low CSF concentration of a dopamine metabolite in tobacco smokers. Am J Psychiatry 156: $130-132$

Gilman SE, Abraham HD (2001). A longitudinal study of the order of onset of alcohol dependence and major depression. Drug Alcohol Depend 63: 277-286.

Goldman D, Dean M, Brown GL, Bolos AM, Tokola R, Virkkunen $M$ et al (1992). D2 dopamine receptor genotype and cerebrospinal fluid homovanillic acid, 5-hydroxyindoleacetic acid and 3methoxy-4-hydroxyphenylglycol in alcoholics in Finland and the United States. Acta Psychiatr Scand 86: 351-357.

Grace AA (2000). The tonic/phasic model of dopamine system regulation and its implications for understanding alcohol and psychostimulant craving. Addiction 95(Suppl 2): S119-S128.

Grant BF (1997). Prevalence and correlates of alcohol use and DSM-IV alcohol dependence in the United States: results of the national Longitudinal Alcohol Epidemiological Survey. J Stud Alcohol 58: 464-473.

Greenfield TK, Weisner C (1995). Drinking problems and selfreported criminal behavior, arrests and convictions: 1990 US alcohol and 1989 county surveys. Addiction 90: 361-373.
Gruenberg AM, Goldstein RD (1997). Depressive disorders. In: Tasman A, Kay J, Lieberman JA (eds) Psychiatry, Vol. 2 WB Saunders Co: Philadelphia. pp 990-1019.

Hamilton M (1960). A rating scale for depression. J Neurol Neurosurg Psychiatry 23: 56-62.

Hawley RJ, Schulman E, Major LF, Poplack J, Catravas GN (1988). Elevated cerebrospinal fluid histidine in alcohol withdrawal. Alcohol 5: 321-323.

Herz LR, Volicer L, D'Angelo N, Gadish D (1990). Additional psychiatric illness by Diagnostic Interview Schedule in male alcoholics. Compr Psychiatry 31: 72-79.

Hesselbrock MN, Meyer RE, Keener JJ (1985). Psychopathology in hospitalized alcoholics. Arch Gen Psychiatry 42: 1050-1055.

Hibbeln JR, Linnoila M, Umhau JC, Rawlings R, George DT, Salem Jr N (1998). Essential fatty acids predict metabolites of serotonin and dopamine in cerebrospinal fluid among healthy control subjects, and early- and late-onset alcoholics. Biol Psychiatry 44: 235-242.

Houston JP, Maas JW, Bowden CL, Contreras SA, McIntyre KL, Javors MA (1986). Cerebrospinal fluid HVA, central brain atrophy, and clinical state in schizophrenia. Psychiatry Res 19: 207-214.

Jones JS, Stanley B, Mann JJ, Frances AJ, Guido JR, TraskmanBendz L et al (1990). CSF 5-HIAA and HVA concentrations in elderly depressed patients who attempted suicide. $A m J$ Psychiatry 147: 1225-1227.

Johnson MR, Lydiard RB, Zealberg JJ, Fossey MD, Ballenger JC (1994). Plasma and CSF HVA levels in panic patients with comorbid social phobia. Biol Psychiatry 36: 425-427.

Kaakkola S, Tuomainen P, Mannisto PT, Palo J (1993). Biogenic amine metabolites in the CSF of patients with late onset and alcoholic ataxias. Acta Neurol Scand 87: 309-311.

Kanemaru K, Mitani K, Yamanouchi H (1998). Cerebrospinal fluid homovanillic acid levels are not reduced in early corticobasal degeneration. Neurosci Lett 245: 121-122.

Kapur S, Mann JJ (1992). Role of the dopaminergic system in depression. Biol Psychiatry 32: 1-17.

Kato N, Takahashi S, Tani N, Iwase N, Odani K (1979). Changes in the metabolism of biogenic amines in alcoholism-especially regarding CSF monoamine metabolites and serum DBH activity. Alcohol Clin Exp Res 3: 24-27.

Koob GF (1992). Neural mechanisms of drug reinforcement. In: Kalivas PW, Samson HH (eds) The Neurobiology of Drug and Alcohol Addiction. New York Academy of Sciences: New York. pp 171-191.

Koslow SH, Maas JW, Bowden CL, Davis JM, Hanin I, Javaid J (1983). CSF and urinary biogenic amines and metabolites in depression and mania. A controlled, univariate analysis. Arch Gen Psychiatry 40: 999-1010.

Limson R, Goldman D, Roy A, Lamparski D, Ravitz B, Adinoff B et al (1991). Personality and cerebrospinal fluid monoamine metabolites in alcoholics and controls. Arch Gen Psychiatry 48: 437-441.

Lindstrom LH (1985). Low HVA and normal 5HIAA CSF levels in drug-free schizophrenic patients compared to healthy volunteers: correlations to symptomatology and family history. Psychiatry Res 14: 265-273.

Lykouras L, Markianos M, Hatzimanolis J, Malliaras D, Stefanis C (1994). Biogenic amine metabolites in delusional (psychotic) depression and melancholia subtypes of major depression. Prog Neuropsychopharmacol Biol Psychiatry 18: 1261-1271.

Major LF, Ballenger JC, Goodwin FK, Brown GL (1977). Cerebrospinal fluid homovanillic acid in male alcoholics: effects of disulfiram. Biol Psychiatry 12: 635-642.

McGrath PJ, Nunes EV, Quitkin FM (2000). Current concepts in the treatment of depression in alcohol-dependent patients. Psychiatr Clin North Am 23: 695-711. 
Modell JG, Mountz JM, Glaser FB, Lee JY (1993). Effects of haloperidol on measures of craving and impaired control in alcoholic subjects. Alcohol Clin Exp Res 17: 234-240.

Moir ATB, Aschcroft GW, Crawford TBB, Eccleston D, Guldberg HC (1970). Cerebral metabolites in cerebrospinal fluid as a biochemical approach to the brain. Brain 93: 357-368.

Murray CJ, Lopez AD (1997). Global mortality, disability, and the contribution of risk factors: global burden of disease study. Lancet 349: 1436-1442.

Nelson CR, Stussman BJ (1994). Alcohol- and drug-related visits to hospital emergency departments: 1992 national hospital ambulatory medical care survey. Adv Data 251: 1-16.

Nemeroff CB, Musselman DL, Nathan KI, Schatzberg AF, Knable MB, Kllinman JE (1997). Pathophysiological basis of psychiatric disorders: focus on mood disorders and schizophrenia. In: Tasman A, Kay J, Lieberman JA (eds) Psychiatry, Vol. 1 WB Saunders Co: Philadelphia. pp 258-295.

Nevo I, Hamon M (1995). Neurotransmitter and neuromodulatory mechanism involved in alcohol abuse and alcoholism. Neurochem Int 26: 305-336.

Nicholls P, Edwards G, Kyle E (1974). Alcoholics admitted to four hospitals in England. II. General and cause-specific mortality. QJ Stud Alcohol 35: 841-855.

Noble EP (1996). Alcoholism and the dopaminergic system A review. Addict Biol 1: 333-348.

Nordin C, Eklundh T, Fernstrom V, Swedin A, Zachau AC (1995). Gradients of CSF monoamine metabolites: a comparison between male and female volunteers. J Psychiatr Res 29: 133-140.

Oquendo MA, Mann JJ (2000). The biology of impulsivity and suicidality. Psychiatr Clin North Am 23: 11-25.

O’Sullivan K, Rynne C, Miller J, O'Sullivan S, Fitzpatrick V, Hux M et al (1988). A follow-up study on alcoholics with and without co-existing affective disorder. Br J Psychiatry 152: 813-819.

Petrakis IL, Trevisan L, D'Souza C, Gil R, Krasnicki S, Webb E et al (1999). CSF monoamine metabolite and beta endorphin levels in recently detoxified alcoholics and healthy controls: prediction of alcohol cue-induced craving? Alcohol Clin Exp Res 23: 1336-1341.

Pihl RO, LeMarquand D (1998). Serotonin and aggression and the alcohol-aggression relationship. Alcohol Alcoholism 33: 55-65.

Placidi GP, Oquendo MA, Malone KM, Huang YY, Ellis SP, Mann JJ (2001). Aggressivity, suicide attempts, and depression: relationship to cerebrospinal fluid monoamine metabolite levels. Biol Psychiatry 50: 783-791.

Post RM, Kotin J, Goodwin FK, Gordon EK (1973). Psychomotor activity and cerebrospinal fluid amine metabolites in affective illness. Am J Psychiatry 130: 67-72.

Quarfordt SD, Kalmus GW, Myers RD (1991). Ethanol drinking following 6-OHDA lesions of nucleus accumbens and tuberculum olfactorum of the rat. Alcohol 8: 211-217.

Raleigh MJ, Brammer GL, McGuire MT, Pollack DB, Yuwiler A (1992). Individual differences in basal cisternal cerebrospinal fluid 5-HIAA and HVA in monkeys. The effects of gender, age, physical characteristics, and matrilineal influences. Neuropsychopharmacology 7: 295-304.

Reddy PL, Khanna S, Subhash MN, Channabasavanna SM, Rao BS (1992). CSF amine metabolites in depression. Biol Psychiatry 31: 112-118.

Reuster T, Rilke O, Oehler J (2002). High correlation between salivary MHPG and CSF MHPG. Psychopharmacology 162: 415-418.

Robinson TE, Berridge KC (1993). The neural basis of drug craving: an incentive-sensitization theory of addiction. Brain Res Rev 18: 247-291.

Roos BE, Silfverskiöld BP (1973). Homovanillic acid in cerebrospinal fluid of alcoholics. $N$ Engl J Med 288: 1358-1359.

Roy A, DeJong J, Lamparski D, Adinoff B, George T, Moore V et al (1991b). Mental disorders among alcoholics. Relationship to age of onset and cerebrospinal fluid neuropeptides. Arch Gen Psychiatry 48: 423-427.

Roy A, DeJong J, Lamparski D, George T, Linnoila M (1991a). Depression among alcoholics. Relationship to clinical and cerebrospinal fluid variables. Arch Gen Psychiatry 48: 428-432.

Roy A, Lamparski D, De Jong J, Adinoff B, Ravitz B, George DT et al (1990). Cerebrospinal fluid monoamine metabolites in alcoholic patients who attempt suicide. Acta Psychiatr Scand 81: $58-61$.

Roy A, Linnoila M (1989). CSF studies on alcoholism and related behaviours. Prog Neuropsychopharmacol Biol Psychiatry 13: $505-511$.

Samson HH, Tolliver GA, Schwarz-Stevens K (1990). Oral ethanol self-administration: a behavioral pharmacological approach to SND control mechanisms. Alcohol 7: 187-191.

Schatzberg AF, Garlow SL, Nemeroff CB (2002). Molecular and cellular mechanisms of depression. In: Davis KL, Charney D, Coyle JT, Nemeroff C (eds) Neuropsychopharmacology: The Fifth Generation of Progress. Lippincott, Williams \& Wilkins: Philadelphia. pp 1039-1050.

Scheinin M, Chang WH, Kirk KL, Linnoila M (1983). Simultaneous determination of 3-methoxy-4-hydroxyphenylglycol, 5-hydroxyindoleacetic acid, and homovanillic acid in cerebrospinal fluid with high-performance liquid chromatography using electrochemical detection. Anal Biochem 131: 246-253.

Schuckit MA (1986). Genetic and clinical implications of alcoholism and affective disorder. Am J Psychiatry 143: 140-147.

Seegal RF (1985). Lumbar cerebrospinal fluid homovanillic acid concentrations are higher in female than male non-human primates. Brain Res 334: 375-379.

Sharma RP, Javaid JI, Faull K, Davis JM, Janicak PG (1994). CSF and plasma MHPG, and CSF MHPG index: pretreatment levels in diagnostic groups and response to somatic treatments. Psychiatry Res 51: 51-60.

Sher KJ, Trull TJ, Bartholow BD, Vieth A (1999). Personality and alcoholism: issues, methods, and etiological processes. In: Leonard KE, Blane HT (eds) Psychological Theories of Drinking and Alcoholism. Guilford Press: New York. pp 54-105.

Soderstrom H, Blennow K, Manhem A, Forsman A (2001). CSF studies in violent offenders. I. 5-HIAA as a negative and HVA as a positive predictor of psychopathy. J Neural Transm 108: 869-878.

Spak L, Spak F, Allebeck P (2000). Alcoholism and depression in a Swedish female population: co-morbidity and risk factors. Acta Psychiatr Scand 102: 44-51.

Spiegel D, King R (1992). Hypnotizability and CSF HVA levels among psychiatric patients. Biol Psychiatry 31: 95-98.

Stanley M, Träskman-Bendz L, Dorovini-Zis K (1985). Correlations between aminergic metabolites simultaneously obtained from human CSF and brain. Life Sci 37: 1279-1286.

Takahashi S, Yamane H, Kondo H, Tani N, Kato N (1974). CSF monoamine metabolites in alcoholism: a comparative study with depression. Folia Psychiatr Neurol 28: 347-354.

Thase ME, Salloum IM, Cornelius JD (2001). Comorbid alcoholism and depression: treatment issues. J Clin Psychiatry 62(Suppl 20): 32-41.

Valenzuela CF, Harris RA (1997). Alcohol: neurobiology. In: Lowinson JH, Ruiz P, Millman RB, Langrod JG (eds) Substance Abuse. A Comprehensive Textbook, 3rd edn Williams \& Wilkins: Baltimore. pp 119-142.

Van Praag HM, Korf J, Lakke JPWF, Schut T (1975). Dopamine metabolism in depressions, psychoses, and Parkinson's disease: the problem of specificity of biological variables in behavior disorders. Psychol Med 5: 138-146.

Vavrousek-Jakuba E, Cohen CA, Shoemaker WJ (1992). Ethanol effects of CNS dopamine receptors: in vivo binding following voluntary ethanol intake in rats. In: Naranjo CA, Sellers EM 
(eds) Novel Pharmacological Interventions for Alcoholism. Springer: New York. pp 372-374.

Vestergaard P, Sorensen T, Hoppe E, Rafaelsen OJ, Yates CM, Nicolaou N (1978). Biogenic amine metabolites in cerebrospinal fluid of patients with affective disorders. Acta Psychiatr Scand 58: 88-96.

Virkkunen M, Eggert M, Rawlings R, Linnoila M (1996). A prospective follow-up study of alcoholic violent offenders and fire setters. Arch Gen Psychiatry 53: 523-529.

Virkkunen M, Rawlings R, Tokola R, Poland RE, Guidotti A, Nemeroff $C$ et al (1994). CSF biochemistries, glucose metabolism, and diurnal activity rhythms in alcoholic, violent offenders, fire setters, and healthy volunteers. Arch Gen Psychiatry 51: 20-27.

Weiss F, Koob GF (1991). The neuropharmacology of ethanol selfadministration. In: Meyer RE, Koob GF, Lewis MJ, Paul SM (eds) Neuropharmacology of Ethanol. Birkhauser: Boston. pp 125-162.
Weiss F, Parsons LH, Schulteis G, Hyytia P, Lorang MT, Bloom FE et al (1996). Ethanol self-administration restores withdrawal-associated deficiencies in accumbal dopamine and 5hydroxytryptamine release in dependent rats. J Neurosci 16: 3474-3485.

Weisbeck GA, Weijers HG, Gross JP (2000). Craving for alcohol and dopamine receptor sensitivity in alcohol-dependent men and coutroe subjects. Neural Transm 107: 691-699.

Westenberg HG, Verhoeven WM (1988). CSF monoamine metabolites in patients and controls: support for a bimodal distribution in major affective disorders. Acta Psychiatr Scand 78: 541-549.

Zucker RA, Gomberg ESL (1986). Etiology of alcoholism reconsidered: the case for a biopsychosocial process. Am Psychol 41: 783-793. 